\title{
STRATEGI KOMUNIKASI DA'WAH USTADZ MUSTOFA MUNTASAM DALAM MENANAMKAN NILA-NILAI KEISLAMAN DI KAMPUNG DUSUN PALIRANGAN-SOLOKURO-LAMONGAN
}

\author{
MUHAMMAD \\ HANIF \\ mubammadhanif@gmail.com \\ Sekolah Tinggi Ilmu Da’wah \\ Mohammad Natsir, Indonesia
}

\author{
MUHAMMAD AMAL \\ SARIFUDIN \\ adamalsarifudin@gmail.com
}

Sekolah Tinggi Ilmu Da'wah

Mohammad Natsir, Indonesia

\begin{abstract}
ABSTRAK
Tujuan Penelitan: Mengetahui Strategi komunikasi Da'wah Ustadz Mustofa Muntasam Dalam Menanamkan Nilai nilai keislaman Di Kampung Dusun Palirangan-Solokuro-Lamongan. Metode Penelitian: Kualitatif. Hasil Penelitian: Strategi Komunikasi Da'wah Ustadz Mustofa Muntasam dalam Menanamkan Nilai-Nilai Keislaman di Kampung Dusun PaliranganSolokuro-Lamongan, adalah menggunakan Teori Stimulus-Respon. Adapun stimulus tersebut diantaranya adalah: (1) Melakukan pendekatan kepada para tokoh baik laki-laki maupun perempuan yang kiranya bisa membantu dalam penyebaran da'wah beliau. (2) Mengadakan Kajian-kajian sebagai wadah dan sarana menanamkan nilai-nilai Keislaman Menjadikan pondok pesantren sebagai pusat berda'wah
\end{abstract}

Kata Kunci: Strategi, Komunikasi Da’wah, Nilai nilai keislaman

\section{PENDAHULUAN}

Ada seorang tokoh yang sangat berpengaruh dalam berda'wah ialah ustadz Mustofa Muntasam, dimana profil tokoh ini termasuk salah satu kader Allahu yarham bapak Moh Natsir yang telah dikirim ke Timur Tengah pada tahun 1982 dan berhasil menyelesaikan perkuliahan belajar di Riyad dan beliau kembali ke dewan da'wah dan ingin mengamalkan ilmunya di dusun Palirangan tempat tinggal sendiri, beliau berperan penting dalam menanamkan nilai-niai keislaman di dusun Palirangan, gaya dan tipe da'wahnya 
adalah sesuatu yang sangat tegas. Secara spesifik, konten da'wah yang disampaikan ustadz bukan konten bawaan satu ormas tertentu, ustadz Mustofa Muntasam adalah ustadz moderat dan ustadz yang berani membawa konten-konten moderat dalam da'wahnya disarang/markas masyarakat Muhammadiyah karena sebelum ustadz Mustofa dikirim dewan da'wah ke Timur Tengah beliau sempat dikirim kepedalamaan di NTT.

Ustadz Mustofa Muntasam juga berperan sangat penting dalam membuka wawasan masyarakat Palirangan tentang aplikasi perbedaan pilihan mazhab atau hal-hal cabang dalam fiqih. Sebagaimana dalam kasus dulu, banyak hal-hal yang terjadi dalam masyarakat seperti Masyarakat sangat sibuk berdebat dan bahkan rela berkelahi dan bermusuhan hanya karena ada satu dua masyarakat yang punya pilihan fiqh yang berbeda.Ustadz Mustofa Muntasam juga berperan penting dalam membangun daya kemampuan masyarakat di Dusun Palirangan. Daya kemampuan sangat penting dalam perkembangan pendidikan dan daya kritis sebuah komunitas. Ustadz Mustofa Muntasam berkomitmen tegas terhadap sunnah Rasul ditengah-tengah masyarakat yang sebelumnya telah kental dengan ajaran nenek moyangnya.

\section{Riwayat Hidup Ustadz Mustofa Muntasam}

Nama asli Ustadz Mustofa Muntasam adalah Mustofa sedangkan nama Muntasam adalah tambahan dari almarhum ayahnya, nama ayah beliau adalah Muntasam Takim dan ibunya bernama Rusim yang merupakan istri pertama dari bapak Muntasam. Ustadz Mustofa mempunyai 6 saudara kandung dan 8 saudara tiri. Beliau lahir pada tanggal 26 Mei 1963 di Dusun Palirangan-Lamongan.

Ia Pernah belajar di MI Palirangan, adapun Tsanawiyah dan Aliyah di pondok pesantren Maskumambang Gresik, kemudian beliau melanjutkan kuliah di IAIN Sunan Ampel hanya 2 sampai 3 bulan. Kemudian Bergabung dengan Dewan Da'wah Islamiyah Indonesia pada tahun 1982 dan menyambi kuliah di Universitas Islam Syeh Yusuf jurusan Aqidah, dan lulus pada tahun 1987 di Tanggerang. Kemudian melanjutkan studinya di Universitas Islam Raja Saud Riyad dengan mengambil jurusan bahasa arab dan kebudayaan Islam. Kemudian beliau juga mengambil jurusan Tarbiyah pada Dirosah Islamiyah, dan melanjutkan lagi setingkat S2 di Tadribul Mualimin Intaqtu Muta'alim pada jurusan Bahasa Arab . 
Ustadz Mustofa aktif dalam berorganisasi seperti di IPM (Ikatan Pelajar Muhammadiyah), IPPM ( Ikatan Pelajar Pondok Pesantren Maskumambang), Dewan Da'wah, DKMPI, KONI, Pramuka, FKAMPUNGI (Forum Komunikasi Pelajar Indonesia Di Arab Saudi), PBB (Partai Bulan Bintang) dari 2003 hingga sekarang, beliaulah yang mengurus $\mathrm{PBB}$ dari wilayah, PBB cabang Lamongan dan Majlis Syuro', dan beliau juga merupakan Ketua Dewan Da'wah Lamongan.

Jabatan yang pernah diemban oleh Ustadz Mustofa ialah sebagai ketua di IPM, KONI, IPPBM, Koperasi Yunit Desa dan FKAMPUNGI. KNPI menjadi Sekretaris, di PBB, dan pernah menjabat sebagai ketua dan ketua majlis pertimbangan wilayah dan wakil ketua pertimbangan wilayah.

Ustadz Mustofa gemar membaca buku buku keagamaan, karenanya beliau mengatakan" Andaikan saya berhenti belajar maka saya akan kalah dengan ummat kita, dan untuk menambah ilmu dan wawasan, sehingga saat berda'wah kita mempunyai inovasi baru ".

Adapun penghargaan yantg pernah beliau peroleh diantaranya adalah ia pernah memperoleh: juara 2 untuk penulisan ilmiyah HANKAM yang diselengarakan oleh kedutaan besar Indonesia di Arab Saudi kemudian dari atasan pendidikan, dari atasan perguruan dan dari kemenag lokal.

Ustadz Mustofa juga pernah dikirim oleh Dewan Da'wah untuk berda'wah ke Timor-Timor, dikirim oleh Diplomat Arab Saudi ke Italy untuk mengajar disana pada tahun 1998, berda'wah di Batam, Sumatra, Sulawesi, dan akhirnya menetap dan berda'wah di Surabaya sejak 2002 sampai sekarang.

Ustadz Mustofa mempunyai beberapa ujian yang dianggap berat yaitu ketika dalam medan da'wah akan tetapi ayahnya sedang sakit, beliau mau meninggalkan jama'ah juga tidak mungkin namun disisi lain yang sakit adalah orang tua, kemudian juga saat istri beliau mau melahirkan tapi beliau sedang di lapangan padahal istri sangat mengharapkan suami ada di sisinya.

Ustadz Mustofa juga mempunyai hal yang berkesan tentunya ketika berda'wah seperti ketika di angkat oleh jama'ah pada saat mau menyebrangi sungai ketika banjir, ketika itu jama'ah berkumpul untuk memikulnya agar tidak basah. 
Kemudian juga ketika krisis bahan bakar, Allah memberikan karomah kepada beliau ketika dulu beliau di Surabaya dan ayah beliau sedang sakit di rumah, maka beliau ditelfon untuk pulang, akhirnya pulanglah beliau pukul sepuluh malam, akan tetapi ditengah perjalanan motor beliau kehabisan bensin dan harus diisi bensin agar bisa jalan kembali, kemudian disaat perjalanan beliau, ditengah hutan motor itu berhenti lalu beliau mengadu kepada Allah SWT, bahwa kepulangan ini, untuk ayah beliau yang sedang sakit, akan tetapi malam itu bensin sudah tidak ada, maka jika engkau Ya Allah bisa menghidupkan orang yang mati maka motor ini jauh lebih muda engkau hidupkan, maka beberapa saat kemudian setelah beliau mengadu, beliau mencoba menghidupkan kembali motor yang tanpa bensin itu, tiba motor itu bisa nyala seperti sedia kala.

Kemudian beliau melanjutkan perjalanannya, namun ditengah perjalanan beliau bertemu seorang anak kecil pada jam dua malam, di pinggir jalan, anak kecil tersebut menawarkan bensin, kemudian ketika beliau berhenti dan membeli bensin lima liter untuk motornya, akan tetapi setelah memasukan bensin itu, kemudian beliau mengambil uang untuk membayarnya, anak kecil itu sudah hilang.. Wallahualam. kejadian seperti itu sering beliau alami ketika dalam berda'wah. Maka dari itu beliau semakin yakin bahwa ketika seorang hamba ikhlas dijalan Allah dan yakin maka akan ditolong oleh Allah dengan berbagai cara.

\section{Sejarah Singkat Kampung Dusun Palirangan}

Asal usul kampung Dusun Palirang menurut para orang tua di daerah tersebut; nama Palirangan bukan nama awal dari daerah tersebut, tetapi nama awalya adalah Kuwirangan yang artinya orangorang pemalu ketika dirinya merasa lebih rendah dari orang lain, daerah ini juga merupakan tempat berkumpulnya para preman, orang kalah judi dan orang-orang nakal pada zaman dahulu. Kemudian nama itu diganti dengan Plirangan kemudian sesaat kemudian diganti lagi menjadi Palirangan, karena arti Plirangan mempunyai makna yang tidak bagus.

Di Dusun Palirangan masyarakatnya berjumlah 2200 orang, 14 RT dan dua RW, kurang lebihnya jumlah laki-laki dan prempuan sekitar 40 rumah dalam 1 RT. 
Kampung Dusun Palirangan terletak di desa Payaman. Dimana desa Payaman terdiri dari 7 dusun :

\begin{tabular}{|c|c|}
\hline Nama Desa & : Desa Payaman \\
\hline Kecamatan & : Solokuro \\
\hline Kabupaten & : Lamongan \\
\hline Kepala Desa & : Chalimin, SPd \\
\hline Sekretaris Desa & : Drs M Baqir Yasin \\
\hline $\begin{array}{ll}\text { Ringin } & : \mathrm{Ke} \\
\text { Sawo } & : \mathrm{Ke} \\
\text { Gayam } & : \mathrm{K} \\
\text { Asem } & : \mathrm{Ke} \\
\text { Palirangan } & \text { Ke } \\
\text { Bango } & : \mathrm{ke} \\
\text { Sejajar } & : \mathrm{Ke} \\
\text { Vilayah Desa }\end{array}$ & $\begin{array}{l}\text { la Dusun Samin Arif } \\
\text { la Dusun Habib Sholeh } \\
\text { ala Dusun Nur 'Aini, S.Pd.i } \\
\text { ala Dusun Abd Muntaqim, } \\
\text { ala Dusun Mushoffan } \\
\text { la Dusun Khozin, S. Pd.i } \\
\text { la Dusun Monaha }\end{array}$ \\
\hline
\end{tabular}

Kampung ini terkenal dengan kampung maling dan prampok, banyak dijumpai orang orang yang mengaku sakti; ada yang bisa menghilang dan ada yang kebal, bisa digambarkan bahwa dulu jika ada orang kehilangan sesuatu, maka mereka akan mencari di kampung ini. Dan tipe masyarakatnya adalah pemberani dan mudah pemberontak jika mereka tidak mau, maka akan tetap tidak mau, dan rata-rata masyarakat disini mempunyai bisnis antar pulau, seperti sapi dan jenis lainya padahal mereka lewat hanya belajar melalui otodidak saja. Dan tranformasi itu sangat cepat. Sehingga masyarakat itu menyerap tradisi dari luar sehingga anak-anak muda dari moral, tradisi dan pakaianya layaknya orang kota padahal mereka orang desa. Kemudian banyak terjadi kesyirikan, mereka mengikuti tradisi nenek moyang, seperti; setiap pernikahan mereka membuka aurat sesuai adat, dan banyak juga tempat tempat yang dianggap kramat.

\section{HASIL DAN DISKUSI}


Dalam hal ini penulis akan menganalisa hasil penelitian. Baik dari hasil wawancara, observasi dan dokumentasi. Penulis akan memaparkan fakta dan data serta melakukan analisis berdasarkan Teori Strategi Komunikasi yang telah penulis tentukan agar dapat menjawab pertanyaan penelitian yang penulis rumuskan.

Pada landasan Teori, penulis memaparkan tentang Teori Stimulus-Respon untuk menganalisis data yaitu:

\section{Komunikasi Lisan (Stimulus)}

Usradz Mustofa Muntasam adalah anak dari ayah Ustadz Muntasam yang tinggal di Dusun Palirangan, beliau meneruskan da'wahnya menggantikan ayahnya di Dusun tersebut karena banyak beliau dapati tatanan dan prilaku masyarakat yang masih menyimpang.

Di Kampung yang dikenal dengan kampung maling dan prampok, inilah Ustadz Mustofa meyusun dan menjalankan strategi da'wah beliau. Berikut strategi strategi da'wah yang beliau lakukan:

a) Menjadikan pondok pesantaren Al-Hikmah yang telah didirikan oleh ayahnya Ustadz Muntasam sebagai pusat berda'wah untuk masyarakat Dusun Palirangan.

b) Mendirikan Masjid Abdullah Al-Ali Al-Mutowwi' pada tahun 2005 untuk tempat beribadah dan menyatukan perbedaan baik antara golongan NU dan Muhammadiyah atau yang lainnya. Dan tujuan Masjid ini juga untuk memberikan contoh akan tata cara pengelolaan dan penggunaan Masjid yang benar sesuai syariat Islam.

c) Mengisi kajian Ibu PKK dari pak Rt sebulan sekali yang dikoordinir dari istri ibu Rt yang jama'ahnya berisi pak Rt, bu Rt dan tamu jajaran di kepala dusun tersebut dalam menankan nilai Islam seperti Aqidah, Sirah Nabawiyah.

d) Membuat Majlis Taklim bagi Ibu-ibu seperti:

a) Taklim Ibu-ibu Aisiyah pada setiap malam senin

b) Taklim Ibu-ibu Nadhadul Aisiyah pada malam jum'at

c) Taklim ibu ibu muslimat pada malam ahad

e) Membuka Travel Umroh dan Haji, serta Membuka Umroh dan Haji gratis bagi warga yang tidak mampu dan bagi marbot" Masjid ataupun warga yang rajin ke Masjid ataupun Mushola. 
f) Memfasilitasi program nikah antar desa artinya beliau berhubungan dengan warga desa lain untuk menjodohkan dengan warga desanya.

g) Membuat GOR yaitu untuk mengakses para anak remaja dalam berolahraga karena dengan begitu para anak remaja akan mudah bergabung mengikuti acara Voly, Sepak Bola dan Takraw akan tetapi sebelum ataupun sesudah mengikuti beliau mengajurkan untuk mengaji dan diberikan tausiyah terlebih dahulu tentang nilai-nilai Islam. Karena banyak dikalangan pemuda yang enggan pergi ke Masjid.

\section{Respon Masyarakat Dusun Palirangan Terhadap Da'wah Ustadz Mustofa Muntasam}

Respon ( $\mathrm{R}$ ) yang dimaksud adalah pengaruh atau akibat yang terjadi kepada masyarakat Kampung Dusun Palirangan yang merasakan keberadaan Ustadz Mustofa Muntasam. dan berikut responnya:

a) Ustadz Mustofa adalah Ustadz yang telah berhasil menggantikan da'wah Ayahnya di kampung tersebut, dan berhasil melanjutkan perjuangan da'wahnya melalui Pesantren Al Hikmah. Ustadz Mustofa Muntasam dikenal dengan Retorika da'wah beliau yang begitu bagus, sehingga para jama'ah sangat antusias dengan kajian - kajian beliau. Dan itu bisa dilihat dari jadwal pengajian beliau yang padat, beliau mendapatkan undangan bukan hanya dari Dusun Palirangan, Desa, Kecamatan, namun juga dari Kota Lamongan seperti Masjid Namira yang terkenal banyak jama'ahnya disetiap jadwal sholat.

b) Dengan mendirikan Masjid Abdullah Al-Ali Al-Mutowwi' pada tahun 2005, saat ini masjid tersebut selalu ramai digunakan untuk sholat lima waktu, dan digunakan untuk kajian serta tempat bertemunya para tokoh di Kampung tersebut.

c) Masyarakat di Dusun Palirangan yang dulunya sangat percaya dengan hari hari yang kramat, tanggal yang kramat, bahkan masih memberikan sesajen ke tempat tempat yang kramat, Alhamdulillah kini sudah tidak mempercayai hal hal kramat tersebut.

d) Ustadz Mustofa Muntasam telah membuka pemahaman wawasan dan kesadaran dalam masyarakat. Dengan pendekatan Da'wah beliau yang lebih menekankan pada pendekatan baik secara personal dan interpersonal. Salah satu contohnya adalah; Dahulu kala dalam hal 
pernikahan atau walimahan, masyarakat Dusun Palirangan lebih menyukai pakaian khas yang membuat aurat mereka terbuka, bahkan setengah tubuhnya terbuka, dan tidak makai jilbab. Namun sekarang setelah sekian tahun akhirnya mereka tersadar dan kebiasaan buruk itu pun mulai hilang.

e) Ustadz Mustofa Muntasam adalah Ustadz yang pertama kali mengajarkan tata cara dalam menjalankan ibadah rukun Islam yang ke-5 yaitu haji seperti dalam program beliau membuka Travel Umroh dan Haji. Padahal dulunya warga beranggapan bahwa pergi haji dan umroh itu sesuatu yang susah. Dan sampai saat ini sudah banyak para warga dan jama'ah yang menunaikan haji melalui perantara travel dan bimbingan beliau.

f) Melalui program nikah antar desa yang dipelopori oleh Ustadz Mustofa, saat ini banyak dijumpai para pemuda dan pemudi penduduk Dusun Palirangan yang menikah dengan para pemuda dan pemudi dari Desa lain maupun dari Kota tertentu.

Semangat belajar pemuda di Dusun Palirangan sekarang sudah sangat baik dibandingkan dahulu, karena mereka semakin faham bahwa; berbekal ilmu itu selalu lebih bermanfaat dan lebih menguntungkan dari pada hanya berbekal harta.

\section{KESIMPULAN}

Berdasarkan pemaparan dan hasil penelitian yang dilakukan oleh penulis maka dapat disimpulkan bahwa; Strategi Komunikasi Da'wah Ustadz Mustofa Muntasam dalam Menanamkan Nilai-Nilai Keislaman di Kampung Dusun Palirangan-Solokuro-Lamongan, adalah menggunakan Teori Stimulus-Respon. Adapun stimulus tersebut diantaranya adalah: (1) Melakukan pendekatan kepada para tokoh baik laki-laki maupun perempuan yang kiranya bisa membantu dalam penyebaran da'wah beliau. (2) Mengadakan Kajian-kajian sebagai wadah dan sarana menanamkan nilai-nilai Keislaman (3) Menjadikan pondok pesantren sebagai pusat berda'wah.

Adapun responnya atau akibat yang timbul dari strategi komunikasi ini adalah masyarakat saat ini secara umum telah melakukan ajaran Islam sesuai Al Qur'an dan Sunnah yang shohih. Diantara bentuk bentuk perubahan yaitu:

1. Dahulu kala dalam hal pernikahan atau walimahan, masyarakat Dusun Palirangan masih cenderung membuka aurat, Namun 
sekarang setelah sekian tahun akhirnya mereka tersadar dan kebiasaan buruk itu pun telah hilang.

2. Masyarakat di Dusun Palirangan yang dulunya sangat percaya dengan hal hal yang kramat dan berbau mistik, namun kini mereka sudah tidak mempercayai hal hal kramat dan mistik tersebut.

3. Semangat dan ghiroh belajar pemuda di Dusun Palirangan sekarang sudah sangat baik, terbukti dengan banyaknya sekolah yang ada di desa tersebut, yakni: PAUD dan SDIT Al Hikmah, MIM 05 Palirangan, MTS Muhammadiyah 12 Palirangan, Pondok Pesantren Al Hikmah dan Pondok Pesantren Darul Ma'arif.

\section{DAFTAR PUSTAKA}

Abd. Mujib, Muhaimin, Pemikiran Pendidikan Islam, Bandung: Bumi Askara, 1991.

Al-Bayununi, Muhammad abu al-fath, al-maddhkal ila ilmu ad da'wah, beirut: massasah ar risalah, 1991

Arifin, Anwar, Strategi Komunikasi, Bandung: Armiko, 1989.

As-Sanafi, Yahya bin Abdullah Strategi Militer Rasulullah `Sang Panglima, (terj. Abu Ihda Husnayain), Solo: Pustaka Arafah, 2003, cet.

Bagul Dagur, Antony, Kredibilitas Komunikator Dalam Perspektif Komunikasi Organisasi, Indo Media, Jakarta: 2004.

Cangra, Hafied, Pengantar Ilmu Komunikasi, Jakarta: Raja Grafindo Persada, 2016, Cet 17.

David, Fred R, Manajemen Strategis, Jakarta: salemba empat, 2002.

Departemen Pendidikan dan Kebudayaan, Kamus Besar Indonesia, Jakarta: Balai Pustaka, 1998, cet.I.

Effendi, Onong Uchajana, Ilmu komunikasi Teori Dan Praktek, Bandung: Remaja Rosda Karya, 2016, cet. XXVII.

Effendy, Onong Uchjana, Ilmu Komunikasi, Teori dan Praktek, Jakarta: PT Remaja Rosdakarya, 1998, cet. II.

Effendy, Onong Uchjana, Ilmu Teori dan Filsafat Komunikasi, Bandung: PT. Citra Aditya Bakti, 2007, Cet. III. 
Ilahi, Wahyu, komunikasi Da'wah, Bandung: Remaja Rosda Karya, 2010

Linda dan Richard Eyre, Mengajarkan Nilai-nilai Kepada Anak, Terj. Alex Tri

Ma'rif, Bambang S., Psikologi Komunikasi Da'wah Suatu Pengantar.

Marison, Manajemen Media Penyiaran Mengelola Radio dan Televisi, Jakarta: kencana pernanda media group, 2011.

Pawit M. Yusuf, M.S, Ilmu Informasi, Komunikasi dan Kepustakaan, Jakarta: PT Bumi Askara, 2013.

Pusat Bahasa Departemen Pendidikan Nasional RI, Kamus Besar Bahasa Indonesia Edisi Ketiga, Jakarta: Balai pusaka, 2005.

Richard West dan Lynn H. Turner, Pengantar Teori Komunikasi, Analisis dan Aplikasi, Jakarta: salemba humanika, hlm. 3 Edisi 3

Ruslan, Rosady, Metode Penelitian, Public Relations dan Komunikasi, Jakarta: Rajawali Pers, 2013, Edisi I.

Suryana, Metodologi Penelitian Model Praktis Penelitian Kualitatif dan kuantitatif, Bandung:: UPI, 2010.

Susilo, Sutarjo Adi, Pembelajaran Nilai-karakter, Jakarta: Raja Grafindo Persada, 2013.

Tim Prodi KAMPUNGI dan KAMPUNGI Stid Mohammad Natsir, Buku Panduan Menyusun Skripsi, Jakarta: STID Mohammad Natsir, 2017.

Widjaja, H.A.W, Komunikasi Komunikasi dan Hubungan Masyarakat, jakarta: PT Bumi askara, 2002, cet IV.

Widodo, Kantjono, Jakarta: Grenmedia Pustaka Utama, 1997, cet, ke-II

WAWANCARA

Muntasam, Muntofa, Ketua Umum Dewan Da'wah Surabaya, Wawacara, Tambun Utara, 6 januari 2019

Muntasam, Mustofa, Ketua Umum Dewan Da'wah Surabaya, Wawancara, Dusun Palirangan, 30 Mei, 2019 
Farida, Hilda, Guru, Wawacara, Dusun Palirangan, 23 desember 2018 .

Setiawan, Agus, Kepala Sekolah, Wawacara, Dusun Palirangan, 1 januari 2019

Mushoffan, Kepala Dusun Palirangan, Wawacara, Dusun

Palirangan, 30 Mei 2019

93 IJurnal Bina Ummat| Vol.1 No.2 |2018 